\title{
Hydrogen recombination on a mixed adsorption layer at saturation on a metal surface: $\mathrm{H} \rightarrow(\mathrm{D}+\mathrm{H})_{\text {sat }}+\mathrm{Ni}(100)$
}

\author{
Ziya B. Güvenç ${ }^{\mathrm{a}, *}$, Dilek Güvenç ${ }^{\mathrm{b}}$ \\ a Department of Electronic and Communication Engineering, Cankaya University, TR-06530 Ankara, Turkey \\ ${ }^{\mathrm{b}}$ Department of Mathematics, Bilkent University, TR-06500 Ankara, Turkey \\ Received 7 November 2002; accepted for publication 10 February 2003
}

\begin{abstract}
Interactions of $\mathrm{H}$ atom beams with $(\mathrm{D}+\mathrm{H})$-covered $\mathrm{Ni}(100)$ surfaces are simulated at saturation level of 0.93 monolayer using quasi-classical microcanonical trajectory method. The Ni substrate is treated as a non-rigid multilayer slab using an embedded-atom method. The model many-body potential energy surface London-Eyring-Polanyi-Sato used to characterize the interactions between $\mathrm{H}-\mathrm{H}$ and $\mathrm{H}-\mathrm{Ni}\left(\begin{array}{lll}1 & 0 & 0\end{array}\right)$ systems parameterized by fitting to the results of detailed total-energy calculations based on density functional theory. Since most of the incident H atoms trap to form hot atoms, reactions between the projectile atom and adsorbates are mainly due to the hot atom process. Results of a linear behavior of the total HD and quadratic behavior of the $\mathrm{D}_{2}$ yields with the initial $\mathrm{D}$ coverage, in addition, significantly low secondary reactions between the adsorbates are found to be in good agreement with the experiment. In addition distributions of the rotational states of the product molecules, molecular desorption angles, vibrational states of the product molecules, molecular formation and desorption time, total and translational energies of the product molecules are also calculated as functions of different $\mathrm{H}$ and $\mathrm{D}$ coverages on the surface.
\end{abstract}

(C) 2003 Elsevier Science B.V. All rights reserved.

Keywords: Hydrogen atom; Deuterium; Nickel; Atom-solid interactions; Metallic surfaces

\section{Introduction}

Eley-Rideal and hot atom reactions of hydrogen atoms with hydrogen-covered single-crystal transition metal surfaces have been extensively studied experimentally [1-16]. In this paper we will focus on a particular experiment [6] which has been kinetics studies, in which the surface is ini-

\footnotetext{
${ }^{*}$ Corresponding author. Tel.: +90-312-284-4500x262; fax: +90-312-284-8043.

E-mail addresses: guvenc@cankaya.edu.tr (Z.B. Güvenç), guvenc@fen.bilkent.edu.tr (D. Güvenç).
}

tially prepared with a known D and $\mathrm{H}$ coverages ( $\mathrm{D}+\mathrm{H}$ mixed coverages), and then exposed to a beam of $\mathrm{H}$ atoms. Initial surface $(\mathrm{D}+\mathrm{H})$ coverages are at saturation level of $0.97 \mathrm{ML}$ prior to reaction measurements (from now on this will be denoted as $\left.(\mathrm{D}+\mathrm{H})_{\text {sat }}\right)$. Fraction of the initial D coverage on the surface in units of monolayers (ML) is varied, and the yields of $\mathrm{HD}, \mathrm{D}_{2}$, and $\mathrm{H}_{2}$ products are determined as a function of the initial D coverage (ML). In order to simulate this experiment we have studied $\mathrm{H} \rightarrow(\mathrm{D}+\mathrm{H})_{\text {sat }}+$ $\mathrm{Ni}\left(\begin{array}{lll}1 & 0 & 0\end{array}\right)$ collision system. While the initial total adsorbates' coverage is kept constant at $0.93 \mathrm{ML}$, percentage of the initial D coverage on the surface 
is varied to mimic the experiment [6]. This coverage level is the theoretical saturation coverage at which molecular formation approximately balances rate of sticking. Therefore in the simulation $0.93 \mathrm{ML}$ is used as the saturation coverage.

Reaction of a projectile (incoming gas-phase hydrogen atom will be denoted as $\mathrm{H}_{\mathrm{p}}$ ) with the metal surface is an exothermic process, and leads to a very "hot" $\mathrm{H}_{\mathrm{p}}^{*}$. This hot atom is highly mobile on the surface. If the $\mathrm{H}_{\mathrm{p}}^{*}$ forms a molecule with a surface adsorbate $\left(\mathrm{H}_{\mathrm{s}}\right.$ or $\left.\mathrm{D}\right)$ before loosing its energy to the metal atoms and/or to the surface adsorbates, the product molecules, $\mathrm{H}_{\mathrm{p}} \mathrm{H}_{\mathrm{s}}$ or $\mathrm{H}_{\mathrm{p}} \mathrm{D}$, can be in highly excited states (ro-vibrational and/ or translational excitations). These reaction channels (between the $\mathrm{H}_{\mathrm{p}}^{*}$ and the surface adsorbates) are the primary reactions which can take place on the surface. Due to the possible multiple collisions between the $\mathrm{H}_{\mathrm{p}}^{*}$, and the $\mathrm{Ni}$ atoms and adsorbates, the total energy distribution of the product molecules is quite wide [17-19]. Their probabilities of formations are much higher than the secondary reactions, formations of the $\mathrm{H}_{\mathrm{s}} \mathrm{H}_{\mathrm{s}}, \mathrm{D}_{2}$, and $\mathrm{H}_{\mathrm{s}} \mathrm{D}$ molecules. Therefore hot atom process dominates the molecular formation on the metal surface. These findings are in agreement with kinetic experiments $[6,16,20,21]$.

We recently studied $\mathrm{D}(\mathrm{H}) \rightarrow \mathrm{H}(\mathrm{D})+\mathrm{Ni}\left(\begin{array}{lll}1 & 0 & 0\end{array}\right)$ collision systems using quasi-classical trajectory methods, and London-Eyring-Polanyi-Sato (LEPS) [22,23] function as the potential energy surface (PES) which was fit to the density functional theory-based total energy calculations [17]. Reactivity and sticking were examined as a function of the surface coverage, to make a connection with the kinetics experiments [6]. Since the quasiclassical trajectory method and the PES used in our present work were discussed in detail in our earlier publications (see e.g., [17-19]), here we will mention only the necessary parts of the modeling of the present work and the PES for the sake of completeness of this presentation.

In this paper we present the results of quasiclassical studies of the reaction of gas-phase $\mathrm{H}_{\mathrm{p}}$ atoms with $(\mathrm{D}+\mathrm{H})_{\text {sat }}$-covered $\mathrm{Ni}\left(\begin{array}{ll}1 & 0\end{array}\right)$, where the lattice atoms are allowed to move. We should mention here that electron-hole pair excitations are not included in this work, which can contribute to adsorbate relaxation on metal surfaces [24-26], and contribution to the hot atom relaxation may be comparable to that of the lattice phonons. Major contribution to the hot atom relaxation comes from the collisions between the hot atom and adsorbates and/or surface metal atoms. Energy transfer from the $\mathrm{H}_{\mathrm{p}}$ to the surface metal atoms is significant only near the initial impact-time, and this energy can be larger than $0.1 \mathrm{eV}$. After the initial impact, energy transfer to the lattice is in some meV range. Since the temperature of the lattice is near $20 \mathrm{~K}$ in our simulation, effect of the lattice phonons on adsorbate relaxation is negligible during the observation time. Quasi-classical methods, the PES, and the total energy calculations used to fit this surface are briefly presented in Section 2. In Section 3 results and discussions are given, and we conclude with a summary.

\section{Potentials and computational procedure}

In our previous works [17-19] we provide detailed descriptions of LEPS PES and the electronic structure calculations used to construct it. Therefore we mention them here only briefly. Ab initio total-energy calculations were performed using VASP (the Vienna ab initio simulation package), developed at the Institut für Materialphysik of the Universitat Wien [27-29]. Interactions of a single $\mathrm{H}$ atom with the metal over three high-symmetry sites; hollow, bridge, and atop, were computed as a function of the distance above the Ni(100) surface. In addition, total energies of two $\mathrm{H}$ atoms over the surface were also calculated (the adsorbate was placed in the hollow site and moved about the minimum, while the incident $\mathrm{H}$ atom was moved from the asymptotic region toward the target in a collinear and various non-collinear configurations important for reactions). Approximately 100 different energy calculations were carried out using DFT for single- and two-H configurations over the $\mathrm{Ni}(100)$. As a result, the parameters of the LEPS function were adjusted by fitting simultaneously to these calculated DFT energies describing the single- and two-H configurations over the $\mathrm{Ni}(100)$ [17] in order to mimic correctly $\mathrm{H} \rightarrow(\mathrm{D}+\mathrm{H})_{\text {sat }}+\mathrm{Ni}\left(\begin{array}{lll}1 & 0 & 0\end{array}\right)$ system. Many- 
body form of the LEPS which is utilized in this work for hydrogen-surface interactions was developed by DePristo and co-workers in their studies of $\mathrm{H}_{2}$ and $\mathrm{D}_{2}$ dissociation on $\mathrm{Ni}$ and $\mathrm{Cu}$ [30-32]. The total energy of the entire system, adsorbates + substrate + projectile atom, is written as $V=V_{\text {EAM }}+V_{\text {LEPS }}$. Here $V_{\text {EAM }}$ is the embedded atom model (EAM), which is an $n$-body PES defining the forces acting on each atom in the substrate (interactions only between the metal atoms). In this potential model the cohesion energy of a metallic system is obtained by the sum of all the interaction energies in $n$-atom system (substrate), and it is expressed as

$V_{\mathrm{EAM}}=\sum_{i}\left[F_{i}\left(\bar{\rho}_{i}\right)+\frac{1}{2} \sum_{j(\neq i)} \phi_{i j}\left(r_{i j}\right)\right]$

where $F_{i}\left(\bar{\rho}_{i}\right)$ is the so-called embedding energy of atom $i$ in the host of the other atoms, $\phi_{i j}\left(r_{i j}\right)$ is the core-core pair interaction between atoms $i$ and $j$, and $r_{i j}$ is the distance between atom $i$ and $j$ (for detail see Refs. $[33,35])$. This potential reproduces numerous properties of bulk $\mathrm{Ni}$ and those of a $\mathrm{Ni}_{2}$ [34], and has been successfully used to study the dynamics and structure of Ni clusters [36-38].

In present work the slab of $\mathrm{Ni}(100)$ is represented by $1197 \mathrm{Ni}$ atoms, seven layers thick, with an approximate surface area of $30 \times 32 \AA^{2}$. Time evolution of the phase space coordinates of all the atoms in the system are evaluated by using Hamming's modified fourth-order predictor-corrector algorithm [39] with an approximate time step of $5 \times 10^{16} \mathrm{~s}$. At time, $t$, equal to zero of each trajectory, the projectile hydrogen, $\mathrm{H}_{\mathrm{p}}$, is placed at $7.0 \AA$ above the surface. The surface contains some mixed coverage of $(\mathrm{D}+\mathrm{H})_{\text {sat }}$ at saturation level (0.93 ML) which is initialized with the ground state zero-point energy. While the total coverage is kept fixed, relative coverages of the adsorbates $\mathrm{H}_{\mathrm{s}}$ and $\mathrm{D}$ are varied in this quasi-classical simulation. The Ni atoms are treated classically without any zero-point energy. Slab's initial temperature is nearly $20 \mathrm{~K}$. In the experiments [6] the surface temperature is at $120 \mathrm{~K}$. Our studies have shown that the thermal energies of the Ni clusters [36-38] and lattice at low temperatures are not important since Ni atoms are heavy. Further, the hot atom energies (on the crystal surface) are on the order of several $\mathrm{eVs}$, and the product distributions have temperatures of thousands of degrees [17].

In the simulation the incident (gas phase) $\mathrm{H}_{\mathrm{p}}$ atoms, with an asymptotic energy of $70 \mathrm{meV}$, are aimed at an area which is a quarter of a square near the center of the surface on the $\mathrm{Ni}(100)$. Each trajectory is followed for up to $2.0 \mathrm{ps}$, using periodic boundary conditions. Since the manybody PESs and their gradients are calculated at each time step by the instantaneous positions of all the H, D, and Ni atoms (over 1200 atoms) in the entire system, time evolution of the collision system is computer intensive. As a result, we run between 4000 and 5000 trajectories for a given initial coverage.

\section{Results and discussion}

The adsorbed $\mathrm{H}_{\mathrm{s}}$ and $\mathrm{D}$ atoms are located in the hollow sites of the $\mathrm{Ni}(100)$, bound by $2.62 \mathrm{eV}$ in the model LEPS PES, which is a little bit less than in the DFT calculations. The H-metal binding over the other surface sites is less, but still on the order of $2 \mathrm{eV}$ or more. Due to the PES, the $\mathrm{H}_{\mathrm{p}}$ atom incident from the gas phase is strongly accelerated towards the metal, and a hot atom, $\mathrm{H}_{\mathrm{p}}^{*}$, forms on the surface. During the initial phase of the collision (between the $\mathrm{H}_{\mathrm{p}}^{*}$ and the surface) the $\mathrm{H}_{\mathrm{p}}^{*}$ can lose more than $0.1 \mathrm{eV}$ to the substrate; energy transfer to the substrate from the $\mathrm{H}_{\mathrm{p}}^{*}$ is the largest during the initial phase of the collision. Afterwards the trajectory of the $\mathrm{H}_{\mathrm{p}}^{*}$ is nearly parallel to the surface, and bounces around. There is in general less energy in the vertical motion of the $\mathrm{H}_{\mathrm{p}}^{*}$.

\subsection{Possible channels}

Inelastic scattering: Inelastic back scattering of the $\mathrm{H}_{\mathrm{p}}$ is within $1 \%$ of the total events. Therefore, forming of trapped hot atoms is highly probable.

Forming HD molecule: The total probability of forming a HD molecule includes: direct $\mathrm{ER}\left(\mathrm{H}_{\mathrm{p}} \mathrm{D}\right)$ reactions within $0.3 \mathrm{ps}$, via $(t>0.3 \mathrm{ps}) \mathrm{H}_{\mathrm{p}}^{*}$ atom D reaction $\left(\mathrm{H}_{\mathrm{p}} \mathrm{D}\right)$, and a hot adsorbate $\mathrm{H}_{\mathrm{s}}^{*}\left(\mathrm{D}^{*}\right)$ $\mathrm{D}\left(\mathrm{H}_{\mathrm{s}}\right)$ reactions $\left(\mathrm{H}_{\mathrm{s}} \mathrm{D}\right)$. Hot $\mathrm{H}_{\mathrm{s}}^{*}$ or $\mathrm{D}^{*}$ atom is 
formed by the collision between the $\mathrm{H}_{\mathrm{p}}^{*}$ and the surface adsorbate $\left(\mathrm{H}_{\mathrm{s}}\right.$ or $\left.\mathrm{D}\right)$. The $\mathrm{H}_{\mathrm{p}}^{*}$ channels dominate formation of the HD molecules.

Forming $\mathrm{H}_{2}$ molecule: Similarly, the total probability of forming an $\mathrm{H}_{2}$ molecule includes: direct ER $\left(\mathrm{H}_{\mathrm{p}} \mathrm{H}_{\mathrm{s}}\right)$, via $(t>0.3 \mathrm{ps}) \mathrm{H}^{* \mathrm{p}}$ atom $\left(\mathrm{H}_{\mathrm{p}} \mathrm{H}_{\mathrm{s}}\right)$, and a hot adsorbate, $\mathrm{H}_{\mathrm{s}}^{*}$, leads to $\mathrm{H}_{\mathrm{s}} \mathrm{H}_{\mathrm{s}}$ formation channels.

Secondary reactions: Secondary reaction, $\mathrm{D}_{2}$ or $\mathrm{H}_{\mathrm{s}} \mathrm{H}_{\mathrm{s}}$, occurs when the $\mathrm{H}_{\mathrm{p}}^{*}$ knocks an adsorbate $\mathrm{H}_{\mathrm{s}} / \mathrm{D}$ atom and free from the adsorbtion site (hollow), and after diffusing this $\mathrm{H}_{\mathrm{s}}^{*}$ or $\mathrm{D}^{*}$ atom reacts with another $\mathrm{H}_{\mathrm{s}}$ or $\mathrm{D}$. These secondary reactions are nearly $10 \%$ of the total molecular formations, and they agree well with the experiment [6].

Subsurface penetration: Further, approximately $14 \%$ of the events end with penetration into the bulk and do not return to the surface within $2.0 \mathrm{ps}$ simulation time. This behavior has been observed for a number of metals, and Küppers and coworkers report that large amounts of $\mathrm{H}$ and $\mathrm{D}$ enter the subsurface region upon exposure of $\mathrm{Ni}\left(\begin{array}{lll}1 & 0 & 0\end{array}\right)$ to atomic beams [5].

Sticking: The remaining trajectories eventually stick into unoccupied hollow sites of the surface.
Energy transfer into the adsorbates should be the primary mechanism for the hot atom relaxation at high coverage. At saturation coverage (0.93 ML) molecular formation approximately balances rate of sticking.

In the experiments, initial desired coverages $(\mathrm{D}+\mathrm{H})_{\text {sat }}$ were formed by first exposing surface to $\mathrm{D}$ atom fluence, in order to establish a specific D coverage. After that the surface was exposed to beams of $\mathrm{H}$ atoms to reach the saturation level. The saturation coverage is reached when the rate of adsorbate removal via (primary and secondary) molecular formation is equal to that of sticking. Experimental [6] saturation coverage level (0.97 ML) is slightly higher than our theoretical saturation coverage of $0.93 \mathrm{ML}$. Küppers and coworkers [6] show that the rate of HD formation increases linear with the initial D coverage. This result is in good agreement with our simulation (see Fig. 1). In our earlier kinetic model work [19] total integrated yields of the HD molecular hydrogen were expressed as a function of the initial D coverage;

HD yield $=\Theta_{\mathrm{D}}(0)-\left[\frac{b}{\left(1-P_{\mathrm{rs}}\right)}\right] \Theta_{\mathrm{D}}^{2}(0)$

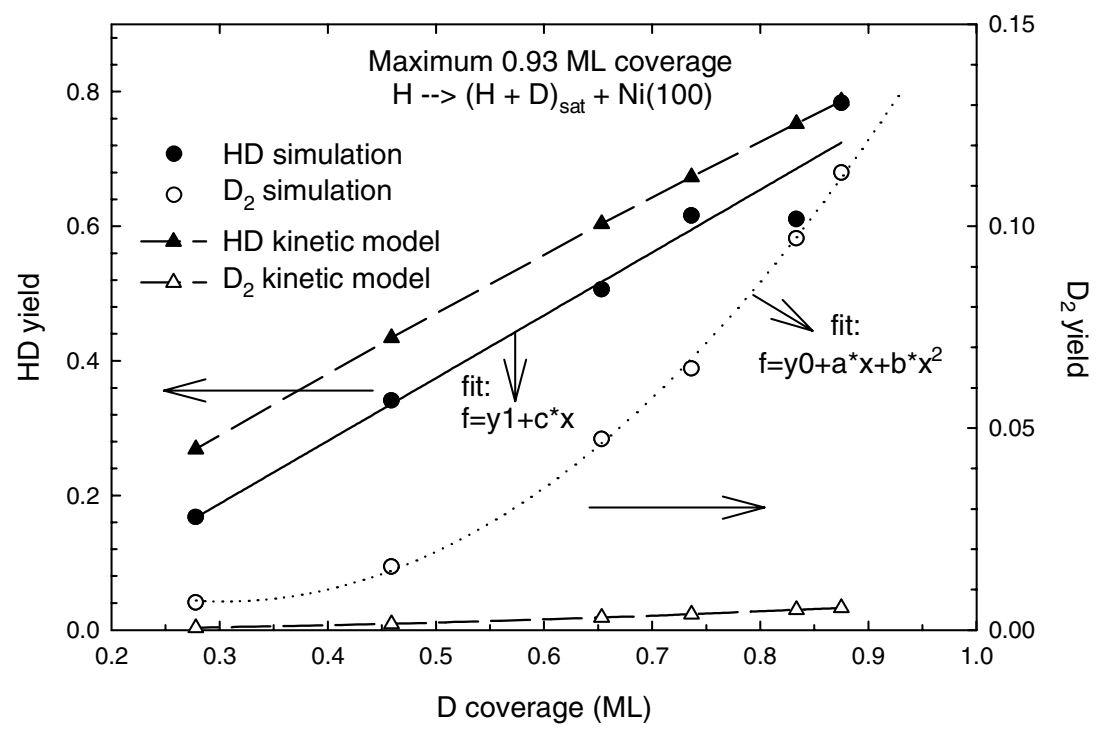

Fig. 1. HD and $\mathrm{D}_{2}$ formation probabilities as a function of the initial D coverage (ML). Data of the HD and $\mathrm{D}_{2}$ simulations are fitted by solid and dotted lines, respectively. Results of the kinetic model are denoted by triangles. 
when $\Theta_{\mathrm{D}}(0)+\Theta_{\mathrm{H}}(0)=$ constant. Here $\Theta_{\mathrm{D}}(0)$ and $\Theta_{\mathrm{H}}(0)$ are the initial D and $\mathrm{H}$ coverages, respectively. The $b$ is a parameter and equal 0.1 (see for details Ref. [19]). The $P_{\mathrm{rs}}$ is the probability of the reflection and penetration into the subsurface (approximately it is equal to 0.14). As seen HD yield is a linear function of the $\Theta_{\mathrm{D}}(0)$, and with a small quadratic term. In Fig. 1 kinetic model and MD simulation results are displayed, as seen, they are both linear in the initial D coverage. However, MD values are slightly smaller than the kinetic and experimental values (kinetic parameters were determined by fitting to the experimental results, see Ref. [19]). In the experiment, subsurface sites are populated by $\mathrm{H}$ and $\mathrm{D}$ atoms. However, in the simulation those sites are unoccupied. Effect of the subsurface $\mathrm{H}$ and $\mathrm{D}$ atoms on the molecular formation and desorption will be studied in the future. At $\Theta_{\mathrm{D}}(0)=0$ coverage the HD yield must be zero, however, for the MD values there is an offset at $0.1 \mathrm{ML}$ if the straight line is extended to zero. This may be due to the fact that at lower D coverages the HD yields are small, therefore, one should look at many more collisions in order to have better converged values. In addition effects of the subsurface hydrogens in this process needs to be determined. On the other hand, the rate of secondary reaction to form $\mathrm{D}_{2}$ scales with the square of the initial D coverage in the experiment. Our calculations also show that the yields of the $\mathrm{D}_{2}$ scale with square of the initial $\mathrm{D}$ coverage. This trend is in good agreement with the experiment. However the $D_{2}$ production is increasing little faster with the initial $\mathrm{D}$ coverage than the experimental values (the $\mathrm{D}_{2}$ formation is over estimated nearly by factor of 2 at the highest $\mathrm{D}$ coverage in the simulation). This was also observed at $0.93 \mathrm{ML}$ of $\mathrm{D}$ coverage in our earlier work on $\mathrm{H} \rightarrow \mathrm{D}+$ $\mathrm{Ni}\left(\begin{array}{lll}1 & 0 & 0\end{array}\right)[17,18]$. In the kinetic work [19] the total integrated yield of the $D_{2}$ as a function of the initial $\mathrm{D}$ coverage at saturation $\left(\Theta_{\mathrm{D}}(0)+\right.$ $\left.\Theta_{\mathrm{H}}(0)=0.93 \mathrm{ML}\right)$ was given

$\mathrm{D}_{2}$ yield $=\left[\frac{b}{2}\left(1-P_{\mathrm{rs}}\right)\right] \Theta_{\mathrm{D}}^{2}(0)$.

As seen, this yield is much less than the yield of the HD and it is in quadratic form. Kinetic model results are less than the MD values as seen in Fig. 1. Experimental integrated yields of the $\mathrm{D}_{2}$ lie in between the MD results and the kinetic model

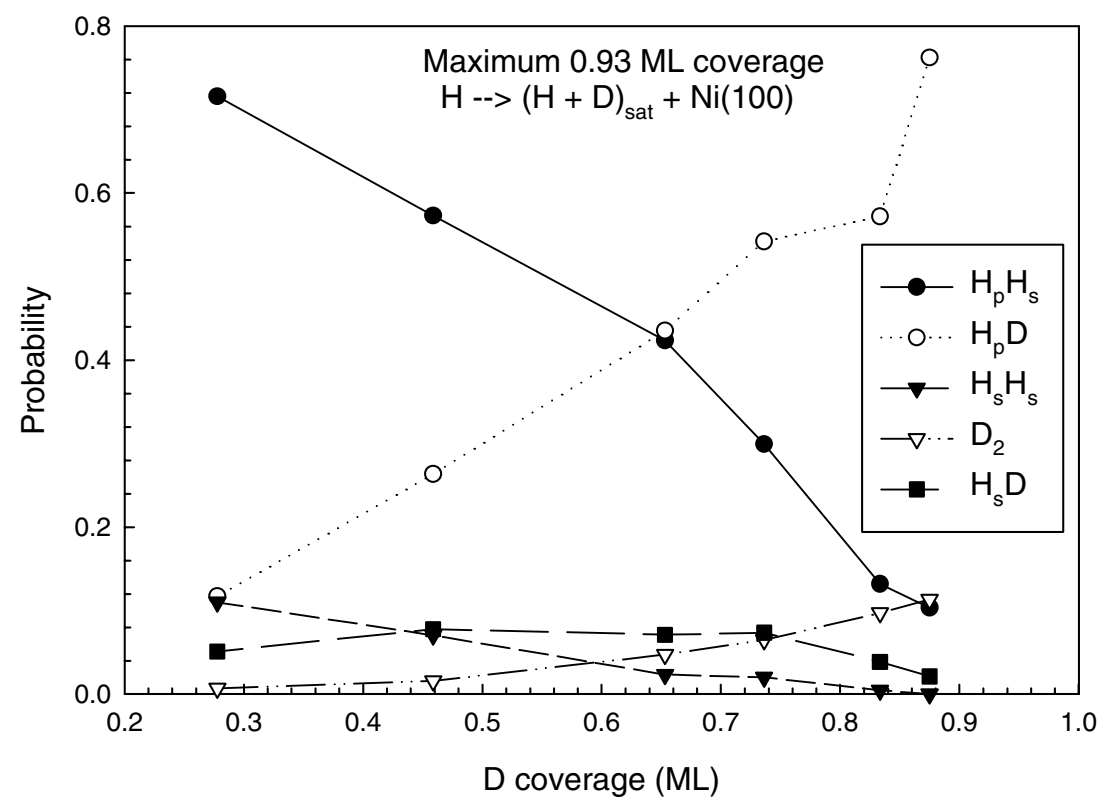

Fig. 2. Probability distributions of all the channels as a function of the initial D coverage (ML). 
values. Since the yields of the $\mathrm{D}_{2}$ formation are quite small, calculated yields in the simulation may also have some convergence problem.

In Fig. 2, channel specific primary and secondary reactions' probabilities are presented. The secondary reactions, $\mathrm{H}_{\mathrm{s}} \mathrm{H}_{\mathrm{s}}, \mathrm{H}_{\mathrm{s}} \mathrm{D}$, and $\mathrm{D}_{2}$, probabilities are less than 0.1 . Further, as the initial D coverage increases, $\mathrm{H}_{\mathrm{p}} \mathrm{D}$ production increases rapidly while $\mathrm{H}_{\mathrm{p}} \mathrm{H}_{\mathrm{s}}$ production decreases as expected. The $\mathrm{H}_{\mathrm{S}} \mathrm{D}$ production is coverage independent between $0.45-0.75 \mathrm{ML}$ of the initial $\mathrm{D}$ coverage. All other productions, especially pri-
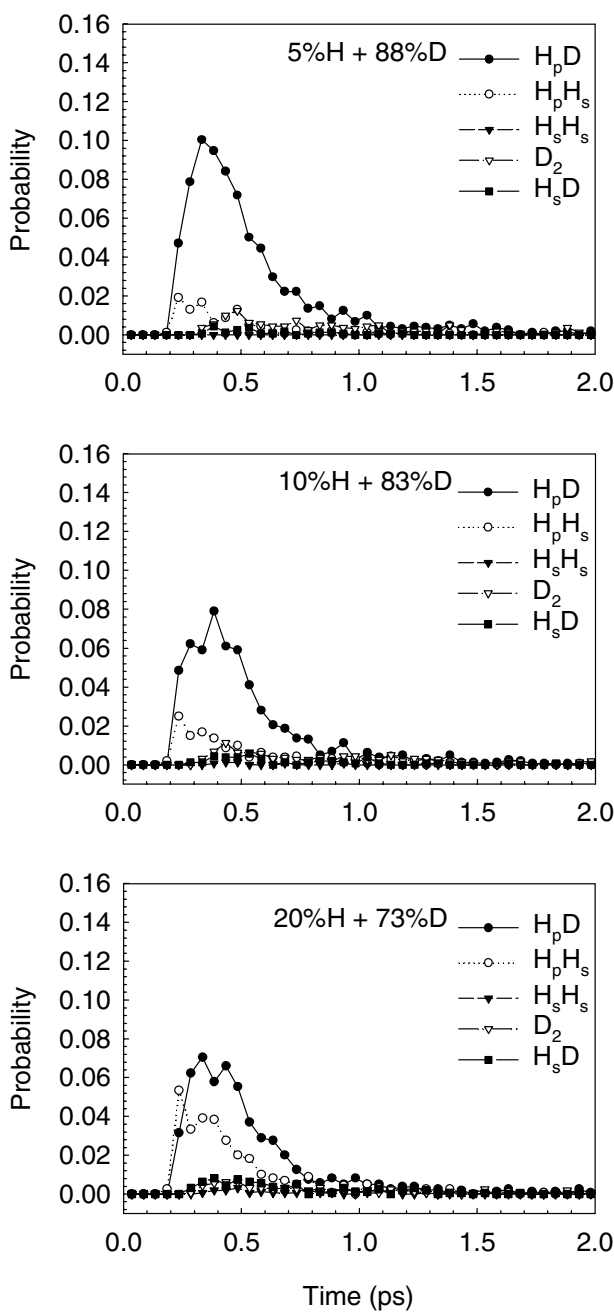

Fig. 3. Probability distributions of the product molecules as a function of time in units of pico seconds for all the surface coverages considered in the simulations.


mary reactions, are more sensitive to the initial $\mathrm{D}$ coverage. Behaviors of the secondary reaction probabilities $\left(\mathrm{H}_{\mathrm{s}} \mathrm{H}_{\mathrm{s}}\right.$, and $\left.\mathrm{D}_{2}\right)$ with respect to each other (in Fig. 2) are more symmetric, i.e., as one of them decreases slowly the other one is increasing gradually, than those of the primary ones.

Probability of molecular formation and subsequent desorption from the surface is presented in Fig. 3 as a function of time. As seen, this is a rapid process and approximately within $1.5 \mathrm{ps}$ time interval molecular desorption is over $(0.1-0.2$ ps of this time frame includes the initial and final flight 
times of the $\mathrm{H}_{\mathrm{p}}$, from the asymptotic region to the surface, and that of the product molecule, from the surface to the asymptotic region, respectively). Direct process occurs at maximum within $0.3 \mathrm{ps}$, i.e, molecular formation process is over within $0.1 \mathrm{ps}$ on the surface. If one compares the distributions of the six different surface coverages (in Fig. 3), one may conclude that (a) time probability distributions of the product molecules are sensitive to the surface coverage (b) the $\mathrm{H}_{\mathrm{p}} \mathrm{H}_{\mathrm{s}}$ formation is somewhat faster than the $\mathrm{H}_{\mathrm{p}} \mathrm{D}$
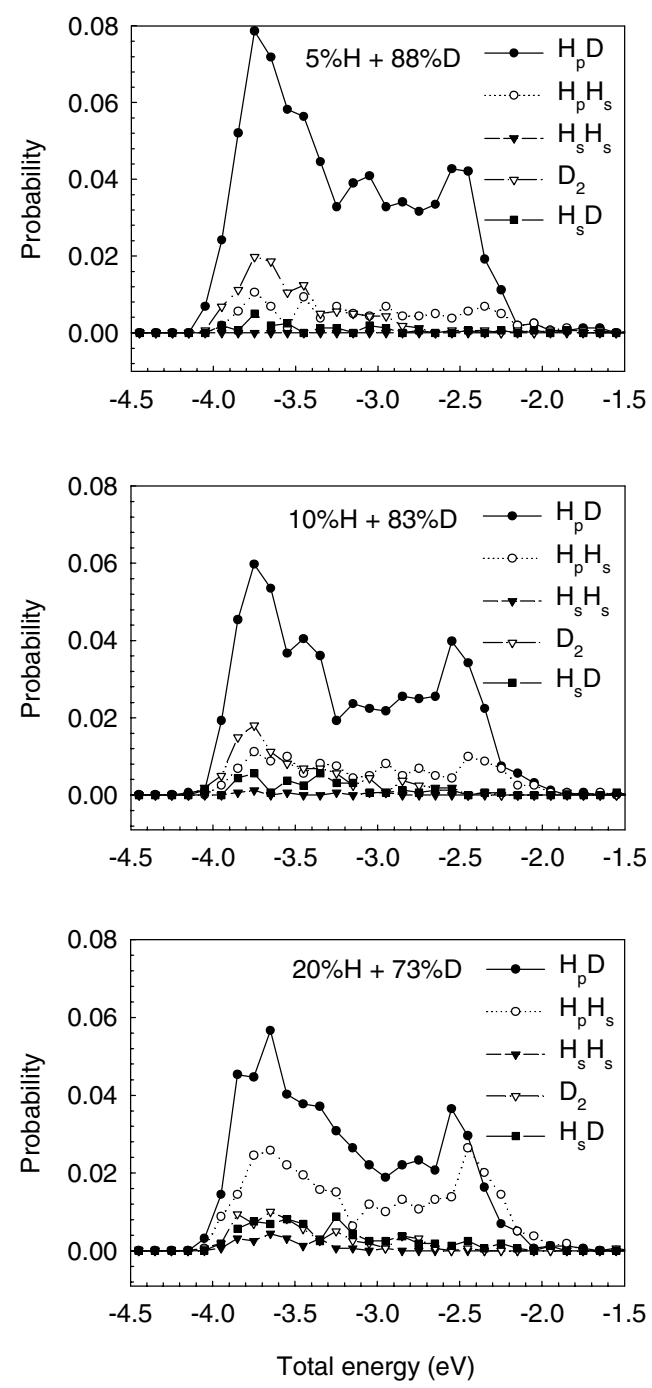

formation at higher $\mathrm{H}$ coverages $\left(\Theta_{\mathrm{H}}(0)>0.19\right.$ $\mathrm{ML}$ ), i.e., $\mathrm{H}_{\mathrm{p}} \mathrm{H}_{\mathrm{s}}$ reaches to the asymptotic region before the $\mathrm{H}_{\mathrm{p}} \mathrm{D}$ molecule since the energy transfer is much more efficient between the hydrogens compared to the $\mathrm{H} \rightarrow \mathrm{D}$ collision, and the $\mathrm{H}_{\mathrm{p}} \mathrm{D}$ is also heavier. (c) The $\mathrm{H}_{\mathrm{p}} \mathrm{D}$ distributions have broader peaks than those of the $\mathrm{H}_{\mathrm{p}} \mathrm{H}_{\mathrm{s}}$. (d) The secondary processes have also broader peaks due to wide time range of the molecular formations because of the multiple collisions between the adsorbates.
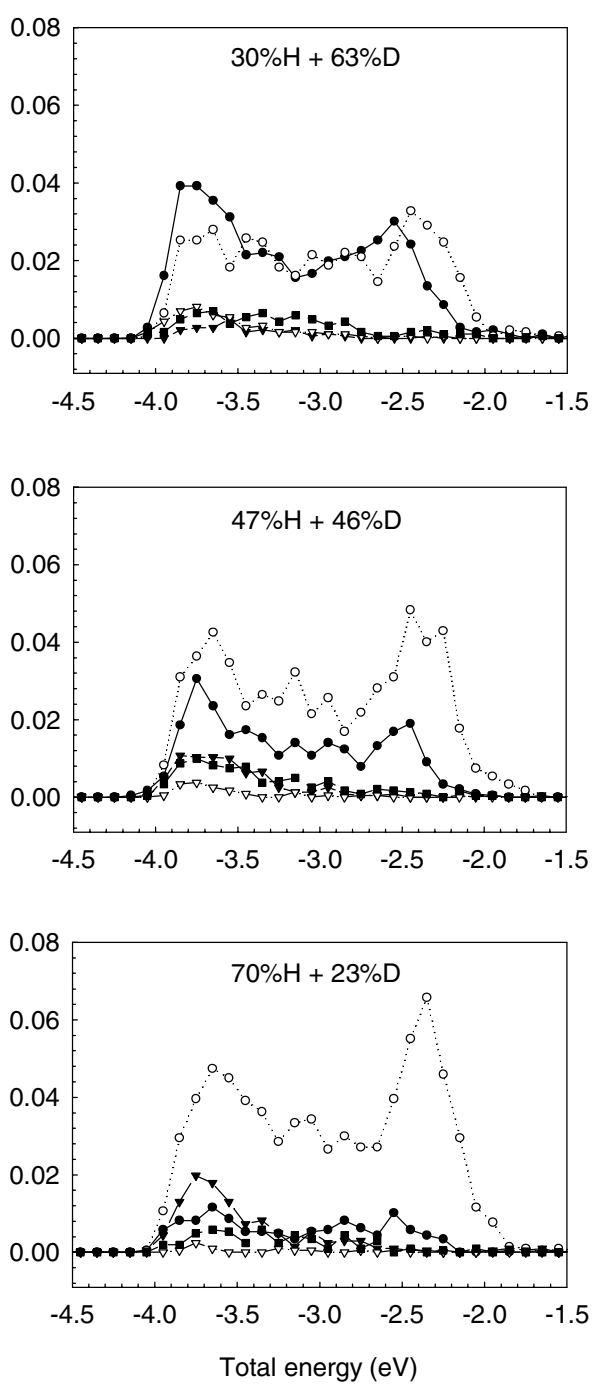

Fig. 4. Same as Fig. 3 for the total energies of the product molecules. 


\subsection{State of the product molecules}

(i) Total energy distributions are presented for all surface coverages in Fig. 4. The prominent features are that the total energy distributions have wide energy range (approximately from -4.0 to $-2.3 \mathrm{eV}$ ) and have two peaks, high and low energy branches. Coverage dependence is clearly visible. The $\mathrm{H}_{\mathrm{p}} \mathrm{D}$ distributions have more pronounced low energy branch at high initial $\mathrm{D}$ coverages. On the other hand, at high $\Theta_{\mathrm{H}}(0)$ values $\mathrm{H}_{\mathrm{p}} \mathrm{H}_{\mathrm{s}}$ distributions have more pronounced high energy com-


ponent. These are due to the efficient energy transfer between the $\mathrm{H}-\mathrm{H}$ collisions, and less energy transfer to the lattice compared to the Dlattice collisions.

(ii) Translational energy distributions peak at about $0.8 \mathrm{eV}$ for all the product molecules (Fig. 5). The full range of the distributions is about $2 \mathrm{eV}$ (from 0.4 to $2.4 \mathrm{eV}$ ). Distributions are not symmetric, i.e., they have long high energy tails, and they are somewhat coverage dependent. The high energy tails are more visible in the case of high $\Theta_{\mathrm{H}}(0)$ coverages for the $\mathrm{H}_{\mathrm{p}} \mathrm{H}_{\mathrm{s}}$ product molecules
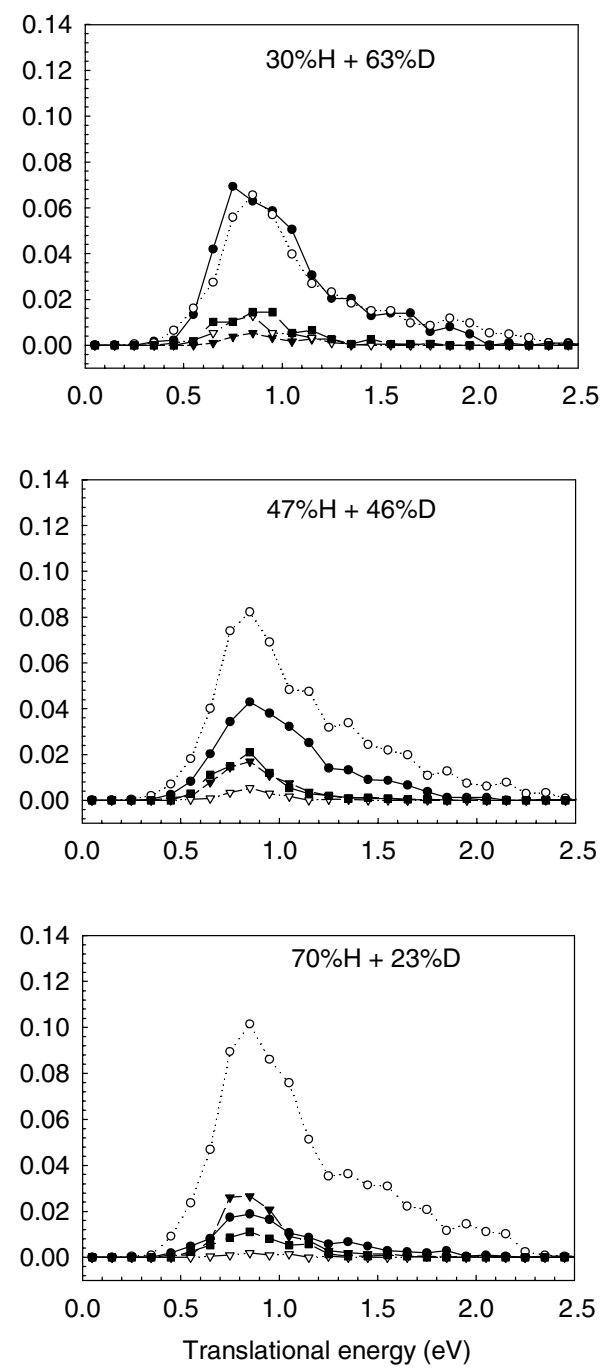

Fig. 5. Same as Fig. 3 for the translational energies of the product molecules. 
since hydrogens lose less energy to the lattice atoms, and more efficient energy transfer between the $\mathrm{H}-\mathrm{H}$ collisions.

(iii) Angular distributions of all the product molecules weakly depend on the surface coverage (Fig. 6). As the initial $\Theta_{D}(0)$ decreases the $\mathrm{H}_{\mathrm{p}} \mathrm{H}_{\mathrm{s}}$ production increases as expected (this is also seen in all other distributions, e.g., Figs. 3-7). Desorption angles with respect to the surface normal approximately vary from 0.8 to $1.5 \mathrm{rad}$.

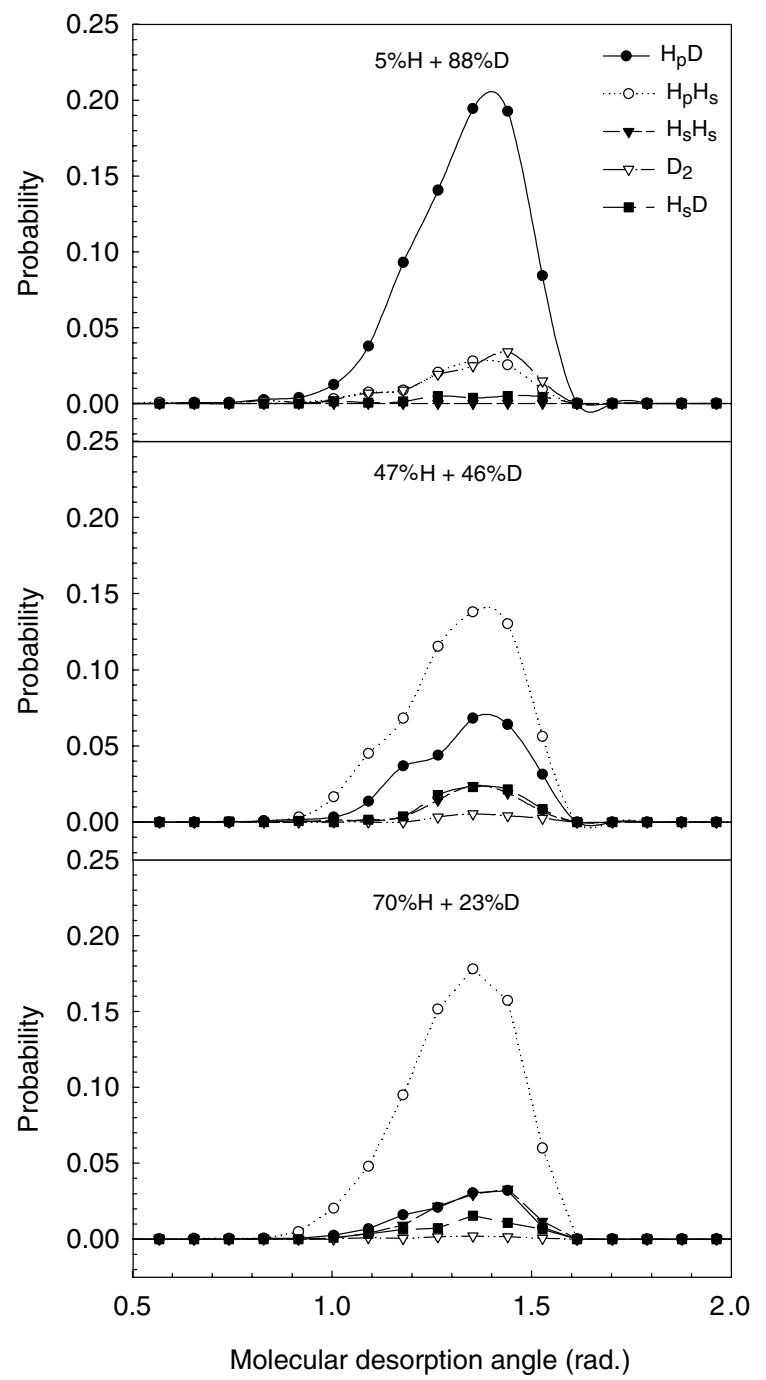

Fig. 6. Probability distributions of the product molecules as a function of molecular desorption angle (rad) for three surface coverages.

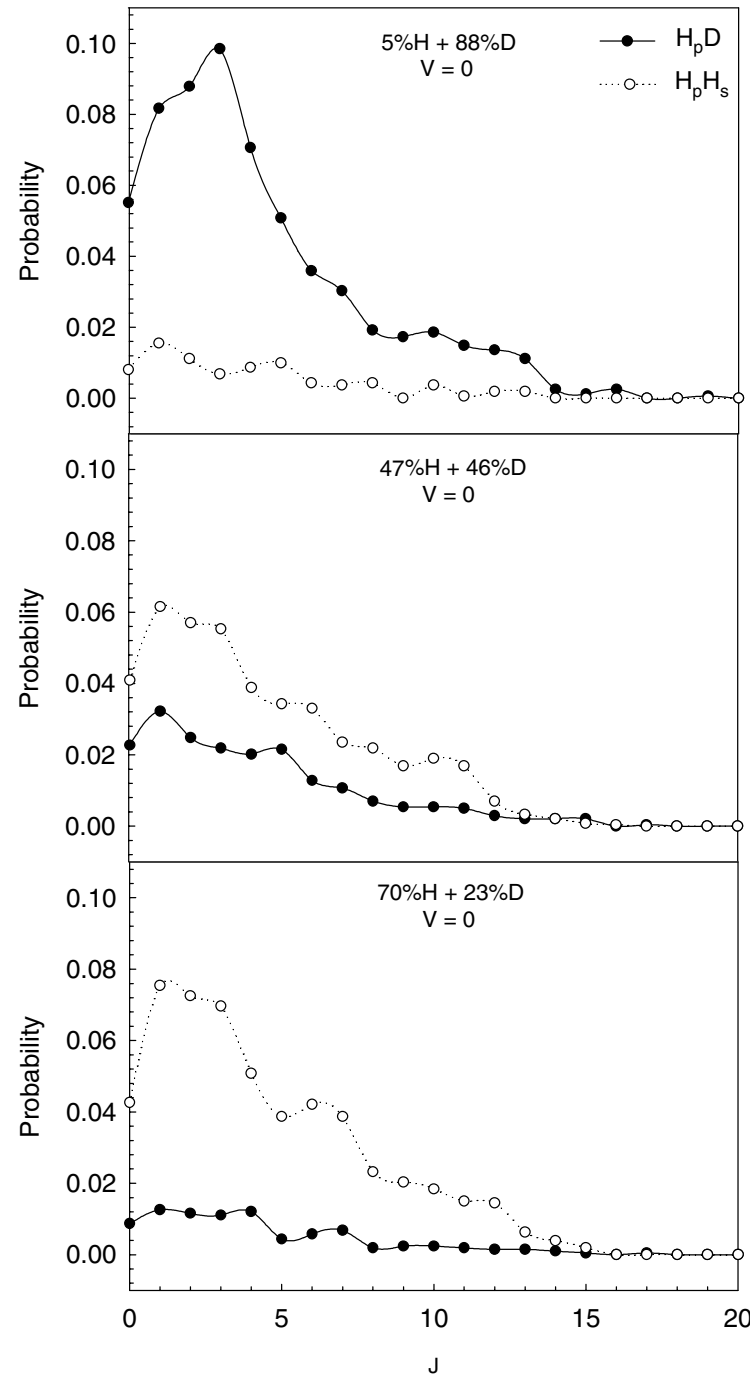

Fig. 7. Same as Fig. 6 for the rotational states of the $H_{p} D$ and $\mathrm{H}_{\mathrm{p}} \mathrm{H}_{\mathrm{s}}$ product molecules at vibrational ground state.

(iv) Rotational state distributions of the $\mathrm{H}_{\mathrm{p}} \mathrm{D}$ and $\mathrm{H}_{\mathrm{p}} \mathrm{H}_{\mathrm{s}}$ molecules at vibrational state $v=0$ for the three different surface coverages, $5 \% \mathrm{H}, 47 \% \mathrm{H}$, and $70 \% \mathrm{H}$ are presented, respectively, in Fig. 7. At high $\Theta_{\mathrm{D}}(0)$ the $\mathrm{H}_{\mathrm{p}} \mathrm{D}$ distribution peaks at rotational state $J=3$. On the other hand, at high $\Theta_{\mathrm{H}}(0)$ coverage the $\mathrm{H}_{\mathrm{p}} \mathrm{H}_{\mathrm{s}}$ distribution peaks at the lower rotational states $(J=1)$. Since HD is an asymmetric molecule (center of mass of the molecule is shifted towards D), it requires less energy for the rotational excitations than an $\mathrm{H}_{2}$, and 

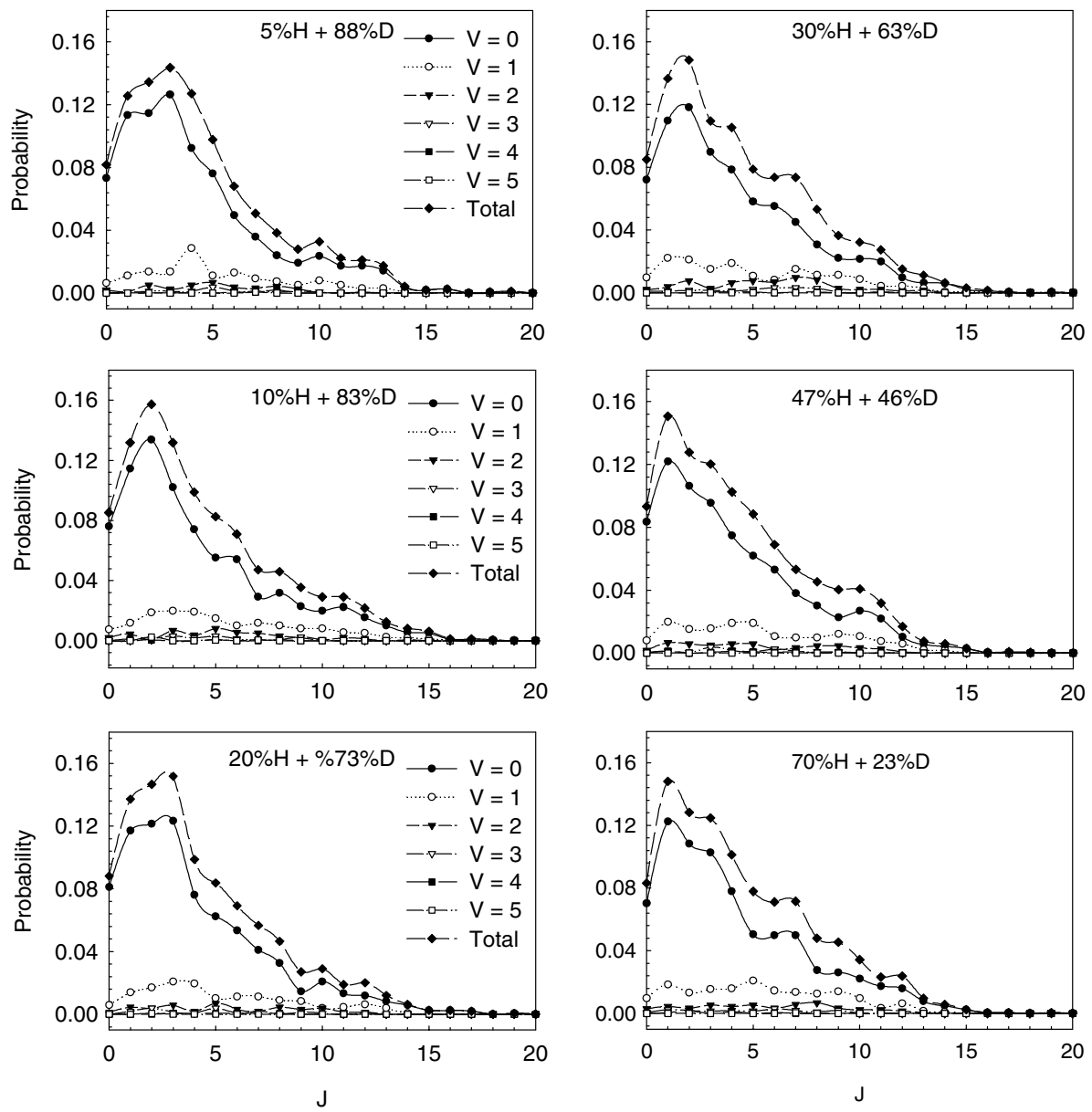

Fig. 8. Same as Fig. 3 for the rotational and vibrational states (summed over rotational states of the product molecules for a given vibrational state).

translational motion of the $\mathrm{H}_{\mathrm{p}} \mathrm{H}_{\mathrm{s}}$ has somewhat higher energy compared to that of the $\mathrm{H}_{\mathrm{p}} \mathrm{D}$. Furthermore, the highest rotational state observed is $J=15$ for these surface coverages.

(v) Rotational state distributions of all the product molecules as functions of the surface coverages and vibrational states of the product molecules observed in the simulations are presented in Fig. 8. Distributions peak between $J=1$ and $J=3$ states. Maximum rotational, and vibrational excitations observed are $J=17$, and $v=54$, respectively. As seen, most of the product molecules are in vibrational ground state: the product molecules are "hot" in rotational, and translational degrees of freedom. (vi) Vibrational distributions are obtained by summing over all rotational states, and product molecules. As seen in Fig. 9 most of the product molecules are in $v=0$ state. This distribution is insensitive to the surface coverage, and the maximum vibrational state observed is $v=5$ among the product molecules.

\section{Summary}

Quasi-classical studies of the interaction of $\mathrm{H}$ atom beams with $(\mathrm{H}+\mathrm{D})_{\text {sat }}$ covered $\mathrm{Ni}\left(\begin{array}{lll}1 & 0 & 0\end{array}\right)$ surface are studied. The total PES allows for motion of the $\mathrm{Ni}$ atoms, as well as penetration of $\mathrm{H}$ and $\mathrm{D}$ 

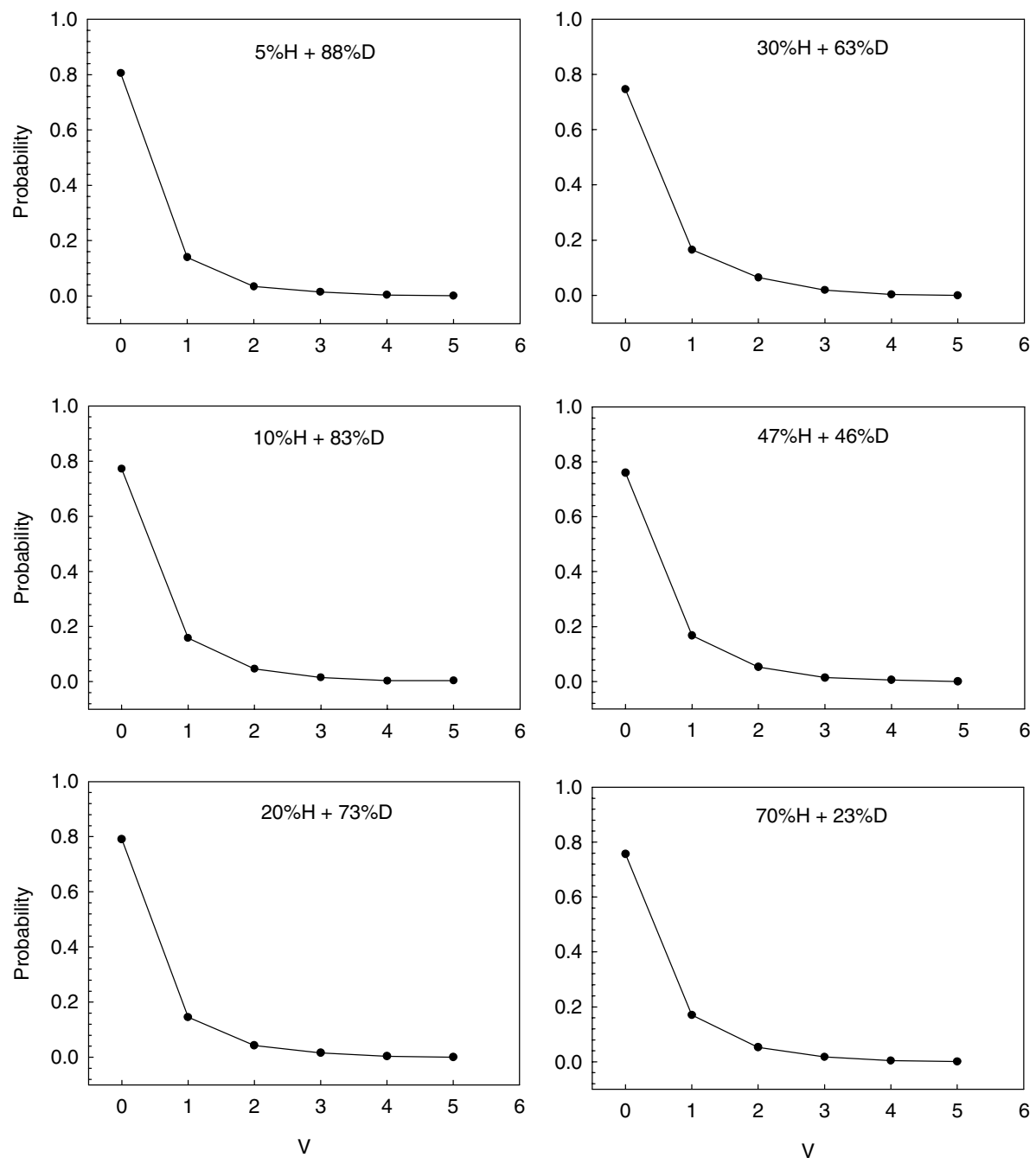

Fig. 9. Probability distributions of all the product molecules as a function of vibrational states (summed over all rotational states and all product molecules).

atoms into the bulk. Reflection of the incident atom is nearly $1 \%$ at all mixed coverages, consistent with the experiments. Maximum energy transfer to the lattice takes place during the initial impact of the gas phase $\mathrm{H}$. This energy transfer can be larger than $0.1 \mathrm{eV}$ for some impact positions. Therefore it is important to treat the lattice non-rigid in the simulation. Experiments [6] show that the rate of HD formation increases linear with the initial D coverage. This trend is in good agreement with our MD calculations, and with the kinetic model values. In the experiment, rate of the secondary reaction $\left(\mathrm{D}_{2}\right.$ formation) scales with the square of the initial D coverage. Our calculations also show that the yields of $\mathrm{D}_{2}$ scale with the square of the initial D coverage. As a result, the trends of our results are in good agreement with the experiment, and with our kinetic model study [19]. However the $D_{2}$ production is increasing little faster than the experimental yields at higher D coverages. On the other hand kinetic model's results remain smaller than the experimental values. The secondary $\mathrm{H}_{\mathrm{s}} \mathrm{H}_{\mathrm{s}}, \mathrm{H}_{\mathrm{s}} \mathrm{D}$, and $\mathrm{D}_{2}$ reactions' probabilities are less than 0.1 . Most of the product 
molecules are "hot" in translational and rotational degrees of freedom, and they are in vibrational ground state.

\section{References}

[1] R.I. Hall, I. Cadez, M. Landau, F. Pichou, C. Schermann, Phys. Rev. Lett. 60 (1988) 337;

C. Schermann, F. Pichou, M. Landau, I. Cadez, R.I. Hall, J. Chem. Phys. 101 (1994) 8152.

[2] P.J. Eenshuistra, J.H.M. Bonnie, J. Los, H.J. Hopman, Phys. Rev. Lett. 60 (1988) 341.

[3] C.T. Rettner, Phys. Rev. Lett. 69 (1992) 383.

[4] C.T. Rettner, D.J. Auerbach, Phys. Rev. Lett. 74 (1995) 4551;

J. Chem. Phys. 104 (1996) 2732;

Surf. Sci. 602 (1996) 357.

[5] Th. Kammler, S. Wehner, J. Küppers, Surf. Sci. 339 (1995) 125.

[6] Th. Kammler, J. Lee, J. Küppers, J. Chem. Phys. 106 (1997) 7362.

[7] S. Wehner, J. Küppers, J. Chem. Phys. 108 (1998) 3353; Surf. Sci. 411 (1998) 46;

T. Zecho, B. Brandner, J. Küppers, J. Surf. Sci. 418 (1998) L26.

[8] Th. Kammler, J. Küppers, J. Chem. Phys. 111 (1999) 8115.

[9] D. Kolovos-Vellianitis, Th. Kammler, J. Küppers, Surf. Sci. 316 (2000) 454.

[10] T.A. Jachimowski, W.H. Weinberg, J. Chem. Phys. 101 (1994) 10997;

Y. Si, W.H. Weinberg, Surf. Sci. 415 (1998) 274;

M.J. Weiss, C.J. Hagedorn, W.H. Weinberg, Surf. Sci. 429 (1999) 54.

[11] G.E. Eilmsteiner, W. Walkner, A. Winkler, Surf. Sci. 263 (1996) 352.

[12] G.E. Eilmsteiner, A. Winkler, Surf. Sci. 366 (1996) L750.

[13] J. Boh, G.E. Eilmsteiner, K.D. Rendulic, A. Winkler, Surf. Sci. 395 (1998) 98.

[14] H. Pölzl, G. Strohmeier, A. Winkler, J. Chem. Phys. 110 (1999) 1154.

[15] J.-Y. Kim, J. Lee, Phys. Rev. Lett. 82 (1999) 1325.

[16] J.-Y. Kim, J. Lee, J. Chem. Phys. 113 (2000) 2856.

[17] Z.B. Güvenç, X. Sha, B. Jackson, J. Chem. Phys. 115 (2001) 9018.
[18] Z.B. Güvenç, X. Sha, B. Jackson, J. Phys. Chem. B 106 (2002) 8342.

[19] B. Jackson, X. Sha, Z.B. Güvenç, J. Chem. Phys. 116 (2002) 2599.

[20] Th. Kammler, S. Wehner, J. Küppers, J. Chem. Phys. 109 (1998) 4071.

[21] Th. Kammler, D. Kolovos-Vellianitis, J. Küppers, Surf. Sci. 460 (2000) 91.

[22] S. Sato, Nippon Kagaku Zasshi 77 (1956) 1202.

[23] A.B. Elkowitz, J.H. McCreery, G. Wolken Jr., Chem. Phys. 17 (1976) 423.

[24] B. Hellsing, M. Persson, Phys. Scr. 29 (1984) 360.

[25] M. Head-Gordon, J. Tully, J. Chem. Phys. 96 (1992) 3939.

[26] G.D. Billing, J. Chem. Phys. 112 (2000) 335.

[27] G. Kresse, J. Hafner, Phys. Rev. B 47 (1993) 558; Phys. Rev. B 49 (1994) 14251.

[28] G. Kresse, J. Furthmuller, Phys. Rev. B 54 (1996) 11169.

[29] G. Kresse, J. Furthmuller, Comput. Mater. Sci. 6 (1996) 15.

[30] C.-Y. Lee, A.E. DePristo, J. Chem. Phys. 85 (1986) 4161.

[31] K. Raghavan, M.S. Stave, A.E. DePristo, J. Chem. Phys. 91 (1989) 1904.

[32] M.J. Scott, E. Zaremba, Phys. Rev. B 22 (1980) 1564; P. Nordlander, S. Holloway, J.K. Norskov, Surf. Sci. 136 (1984) 59.

[33] M.S. Foiles, M.I. Baskes, M.S. Daw, Phys. Rev. B 33 (1986) 7983.

[34] A.F. Voter, S.P. Chen, in: R.W. Siegal, J.R. Weetman, R. Sinclair (Eds.), Characterization of Defects in Material, MRS Symposia Proceedings 82, Materials Research Society, Pittsburgh, 1987, pp. 175-180.

[35] A.F. Voter, Los Alamos Unclassified Technical Report No. LA-UR 93-3901, Los Alamos National Laboratories, Los Alamos, 1993.

[36] Z.B. Güvenç, J. Jellinek, A.F. Voter, in: P. Jena, S.N. Khanna, B.K. Rao (Eds.), Physics and Chemistry of Finite Systems From Clusters to Crystals, Vol. I, Kluwer Academic, Dordrecht, 1992, p. 411.

[37] Z.B. Güvenç, J. Jellinek, Z. Phys. D 26 (1993) 304.

[38] J. Jellinek, Z.B. Güvenç, in: L.J. Farrugta (Ed.), The Synergy Between Dynamics and Reactivity at Clusters and Surfaces, Kluwer, Dordrecht, 1995, p. 217, and references therein.

[39] R.W. Hamming, Numerical Methods for Scientists and Engineers, McGraw-Hill, New York, 1962. 